\title{
Cyclic nucleotide-gated ion channel 6 mediates thermotolerance in Arabidopsis seedlings by regulating nitric oxide production via cytosolic calcium ions
}

\author{
Xuan Peng ${ }^{\dagger}$, Xiaona Zhang ${ }^{\dagger}$, Bing Li and Liqun Zhao* ${ }^{*}$
}

\begin{abstract}
Background: We previously reported the involvement of nitric oxide (NO) and cyclic nucleotide-gated ion channel 6 (CNGC6) in the responses of plants to heat shock (HS) exposure. To elucidate their relationship with heat tolerance in Arabidopsis thaliana, we examined the effects of HS on several groups of seedlings: wild type, cngc6, and cngc6 complementation and overexpression lines.

Results: After HS exposure, the level of NO was lower in cngc6 seedlings than in wild-type seedlings but significantly elevated in the transgenic lines depending on CNGC6 expression level. The treatment of seeds with calcium ions $\left(\mathrm{Ca}^{2+}\right)$ enhanced the NO level in Arabidopsis seedlings under HS conditions, whereas treatment with EGTA (a $\mathrm{Ca}^{2+}$ chelator) reduced it, implicating that CNGC6 stimulates the accumulation of NO depending on an increase in cytosolic $\mathrm{Ca}^{2+}\left(\left[\mathrm{Ca}^{2+}\right]_{\text {cyt }}\right)$. This idea was proved by phenotypic observations and thermotolerance testing of transgenic plants overexpressing NIA2 and NOA1, respectively, in a cngc6 background. Western blotting indicated that CNGC6 stimulated the accumulation of HS proteins via NO.
\end{abstract}

Conclusion: These data indicate that CNGC6 acts upstream of NO in the HS pathway, which improves our insufficient knowledge of the initiation of plant responses to high temerature.

Keywords: Arabidopsis, Cyclic nucleotide-gated ion channel 6, Heat shock, Heat shock protein, Nitric oxide

\section{Introduction}

Plant growth is governed by many environmental factors, including heat shock (HS), which always causes serious damage to plants. Sublethal heat exposure initiates defensive reactions in cells and prevents them from subsequent lethal heat exposure. For example, HS proteins (HSPs) play an important role in cellular responses under HS conditions. Some HSPs act as molecular chaperones to counteract protein denaturation and aggregation; however, other HSPs, such as ubiquitin and certain proteases, target nonnative proteins for degradation [1]. Thus, the regulation of HSP synthesis is an particularly important issue in plant thermotolerance.

* Correspondence: zhaolq70@163.com

${ }^{+}$Xuan Peng and Xiaona Zhang contributed equally to this work.

College of Life Sciences, Hebei Normal University, Shijiazhuang 050024, China
Nitric oxide (NO) is a key signaling molecule that participates in a number of processes throughout the life cycle of plants, including seed germination and dormancy, plant growth and development, flowering, and the interactions of plants with biotic or abiotic stresses $[2,3]$. Arginine-denpendent NO synthase (NOS) and nitrite-dependent nitrate reductase (NR) are two important enzymes for NO production in plants. The physiological function of NOS has attracted significant interest. $\mathrm{L}$-arginine, $\mathrm{NADPH}$, and $\mathrm{O}_{2}$ are its substrates; they are used to produce $\mathrm{NO}, \mathrm{NADP}^{+}$, and citrulline [4]. Nitric oxide-associated protein 1 (NOA1), is involved in the regulation of NO levels in Arabidopsis thaliana (hereafter, Arabidopsis) [5, 6]. Although the mechanism whereby NOA1 affects NO production in plants has not been throughly elucidated, noa1, which exhibits an

(c) The Author(s). 2019 Open Access This article is distributed under the terms of the Creative Commons Attribution 4.0 International License (http://creativecommons.org/licenses/by/4.0/), which permits unrestricted use, distribution, and 
reduced endogenous $\mathrm{NO}$ level, is also a valuable material for studies on NO function in plant.

$\mathrm{NR}$, an essential cytosol-located enzyme for nitrogen assimilation, is also an important source of NO for plants [7]. Under normal conditions, it preferentially reduces nitrate to nitrite [8]. In comparison, under extreme growth conditions, NR can transfer electrons from $\mathrm{NAD}(\mathrm{P}) \mathrm{H}$ to $\mathrm{NO}_{2}{ }^{-}$to induce the biosynthesis of NO. NR plays a central role in regulating NO production in response to biotic or abiotic stresses. Two highly homologous NRs, nitrate reductase 1 (NIA1) and nitrate reductase 2 (NIA2), have been identified in Arabidopsis. Although the amino acid sequences of NRs are highly conserved, NIA2 shows greater activity than NR1, accounting for about $90 \%$ of the total NR activity in plant cells [9].

As an extensively distributed signaling molecule, NO has been found to increase plant tolerance to many environmental factors, including drought, salinity, heavy metals, and disease [2]. Additionally, we even reported that an increase of $\mathrm{NO}$ following extreme heat exposure is crucial for plant acclimation to heat stress [10], inconsistent with a previous findings [11], which might be due to light, age, and temperature effects on NO production, as shown in our previous work [12] (see Supplementary Fig. S3). In a recent review [13], a model was presented that over-accumulation of $\mathrm{NO}$ induces heat-sensitive phenotypes (and that can be rescued with NO scavengers), in consistent with our former conclusion [10] that only a moderate NO increase could cause increased heat tolerance (see Fig. 2).

We previously reported that hydrogen peroxide $\left(\mathrm{H}_{2} \mathrm{O}_{2}\right)$ stimulated the production of $\mathrm{NO}$, which in turn regulated the downstream protein calmodulin3 (CaM3) to promote thermotolerance depending on increased HSP accumulation [12]. Interestingly, our subsequent work showed that $\mathrm{H}_{2} \mathrm{O}_{2}$-induced $\mathrm{NO}$ stimulated the activities of antioxidant enzymes so as to eliminate excessive $\mathrm{H}_{2} \mathrm{O}_{2}$, indicating a feedback inhibition between $\mathrm{H}_{2} \mathrm{O}_{2}$ and $\mathrm{NO}$ in thermotolerance [14]. Though NO plays an important role in thermotolerance, the precise mechanism underlying its induction remains unclear. Further study of this aspect of HS signaling will enrich our understanding of heat tolerance.

Cyclic nucleotide-gated cation channels (CNGCs) are non-selective cation-conducting channels that are activated by cyclic nucleotide monophosphate or hyperpolarization. In plants, CNGCs function in signaling pathways that may be tied to their ability to conduct calcium ions $\left(\mathrm{Ca}^{2+}\right)$ rather than other cations into plant cells [15]. $\mathrm{Ca}^{2+}$ mobilization is a central issue in various plant signaling pathways. The Arabidopsis genome contains 20 expressed CNGC genes that have both distinct and shared biological activities [16]. For example, CNGC14-dependent $\mathrm{Ca}^{2+}$ signaling plays a direct role in mediating the early posttranscriptional phase of auxin growth responses in Arabidopsis roots [17]. In comparison, Arabidopsis CNGC2 is associated with a jasmonic acid-induced apoplastic $\mathrm{Ca}^{2+}$ influx in epidermal cells [18]. Among the eight $\mathrm{Ca}^{2+}$ channels in Arabidopsis (including six CNGCs and two glutamate receptor-like channels), CNGC18 is the only one that is critical for pollen tube guidance [19]. However, the function and regulation of plant CNGCs have not been thoroughly evaluated as major issues in plant science.

CNGCs are also thought to mediate $\mathrm{Ca}^{2+}$ signaling in the HS pathway. We found that a heat-activated plasma membrane (PM) $\mathrm{Ca}^{2+}$-permeable channel, CNGC6, is involved in the expression of HSP genes and acquisition of thermotolerance in Arabidopsis seedlings [20]. In pollen, AtCNGC16 is essential for heat tolerance during pollen development [21]. Conversely, CNGC2 deficiency results in elevated thermotolerance of plants, indicating its negative role in inducing thermotolerance of Arabidopsis plants [22]. These reports might indicate that some CNGCs in Arabidopsis are stimulated by high temperatures and mediate HS signaling at different growth stages.

Over the past several years, an increasing number of studies have considered a close relationship between NO and $\mathrm{Ca}^{2+}$ signaling in plants. $\mathrm{Ca}^{2+}$ and $\mathrm{NO}$ are well established as universal intracellular second messengers [23]. Studies of plants have shown remarkable overlap in their individual pathways; however, it remains controversial which is downstream of the other. Numerous studies point to a specific role for $\mathrm{NO}$ in regulating $\mathrm{Ca}^{2+}$ signaling. For example, $\mathrm{NO}$ released by $\mathrm{NO}$ donors induced a transient rise in cytosolic $\mathrm{Ca}^{2+}\left(\left[\mathrm{Ca}^{2+}\right]_{\mathrm{cyt}}\right)$ in Nicotiana plumbaginifolia cells [24]. In contrast, some studies have assessed the role of $\mathrm{Ca}^{2+}$ in initiating NO signaling. For example, in several plant species, $\mathrm{Ca}^{2+}$ and $\mathrm{CaM}$ act as cofactors to stabilize plant NOS activity and NO accumulation, suggesting that $\mathrm{Ca}^{2+}$ or $\mathrm{Ca}^{2+}-\mathrm{CaM}$ directly interact with a NOS-like enzyme in plants [8]. As yet, the relationship between $\mathrm{NO}$ and $\mathrm{Ca}^{2+}$ is obscure in plants exposed to high temperatures.

In this study, we used the model plant Arabidopsis to explore the functions of $\mathrm{NO}$ and the $\mathrm{Ca}^{2+}$-permeable channel CNGC6 in high heat conditions. Our results demonstrate the involvement of CNGC6 in NO signaling as an upstream factor in the HS signaling pathway.

\section{Results}

Effects of HS on NO accumulation in the seedlings of wild type, cngc6, a complemented line, and an overexpression line

$\mathrm{NO}$ is a plant signaling molecule that plays a crucial role in the response to many environmental stresses, including HS [2]. Numerous studies indicate a specific role for CNGCs in controlling NO accumulation [25]. To investigate the 
relationship between $\mathrm{CNGC6}$ and $\mathrm{NO}$ in thermotolerance, we first examined endogenous $\mathrm{NO}$ accumulation at the seedling stage using wild-type plants, a T-DNA insertion mutant (cngc6; SALK_042207), a complementation line (COM12; cngc6 + CNGC6), and a CNGC6 overexpression line (OE8; ecotype Columbia [Col] + CNGC6) [20]. Intracellular NO formation was examined with the fluorescent probe 4-amino-5-methylamino-2', $7^{\prime}$-difluorofluorescein diacetate (DAF-FM DA), which can permeate the membrane and be transformed by intracellular esterases into 4amino-5-methylamino-2',7'-difluorofluorescein (DAF-FM). It does not directly react with the NO free radical, but rather with nitrous anhydride to yield a highly fluorescent triazole compound [26].

Fluorescence analysis indicated that under normal growth conditions $\left(22^{\circ} \mathrm{C}\right)$, no clear difference in $\mathrm{NO}$ abundance existed among the seedlings. After HS treatment at $45^{\circ} \mathrm{C}$ for $60 \mathrm{~min}$ [10], the NO level increased by $273 \%$ in wild-type seedlings. This is greater than the increase observed in cngc6 (213\%); however, the NO level was nearly completely rescued in COM12 seedlings (269\%), and even higher in OE8 seedlings (310\%) than in wild-type seedlings (Fig. 1a, b). These data show that the variation in $\mathrm{NO}$ observed following $\mathrm{HS}$ treatment was dependent on CNGC6 expression.

\section{Effect of $\mathrm{Ca}^{2+}$ on the NO level in wild-type seedlings}

CNGC6 is a heat-activated $\mathrm{Ca}^{2+}$-permeable channel in the plasma membrane (PM) of plant cells [20]. $\mathrm{Ca}^{2+}$, probably the most versatile ion found in eukaryotes, has been confirmed to coordinate with $\mathrm{NO}$ in several physiological processes [8]. Thus, we inferred that CNGC6 promotes the accumulation of NO through $\mathrm{Ca}^{2+}$ to mediate thermotolerance.

To verify this hypothesis, we examined the NO levels in wild-type, cngc6, and OE8 seedlings that had been pretreated with $5 \mathrm{mM} \mathrm{CaCl}$ or $2 \mathrm{mM}$ EGTA $\left(\mathrm{a} \mathrm{Ca}^{2+}\right.$ chelator) before germination [27]. Fluorescence analysis showed no obvious difference in NO levels among the seedlings under normal conditions. Under HS conditions, treatment with $5 \mathrm{mM} \mathrm{Ca}^{2+}$ increased the $\mathrm{NO}$ level to 389,326 , and $407 \%$ of their individual controls, respectively, in wild-type, cngc6, and OE8 seedlings. Whereas $2 \mathrm{mM}$ EGTA reduced the increase in NO to 219,187 , and $227 \%$ of their individual controls, respectively, in wild-type $c n g c 6$, and OE8 seedlings (Fig. 1c, d).

\section{Effects of NO on the thermotolerance of cngc6 seedlings}

Next, we examined the effects of the exogenous application of two NO donors, sodium nitroprusside (SNP) and $S$-nitroso- $N$-acetylpenicillamine (SNAP), on the thermotolerance of $c n g c 6$ seedlings.

Fluorescence analysis revealed that both of SNP and SNAP $(20 \mu \mathrm{M}$ each) increased the amount of NO in wild-type and cngc6 plants under normal and HS conditions; moreover, the effect was particularly pronounced for SNP (Fig. 2a, b). To measure physiological adaptability to heat stress, survival ratios were calculated for plants following $\mathrm{HS}$ treatment at $45^{\circ} \mathrm{C}$ for $100 \mathrm{~min}$ and 5 days of recovery at $22^{\circ} \mathrm{C}$ [28]. Under normal growth conditions $\left(22^{\circ} \mathrm{C}\right)$, no obvious phenotypic difference was observed between wild-type and cngc6 seedlings (Fig. 2c, Control). After HS treatment, the survival ratio of the wild-type seedlings (48\%) was higher than that of $c n g c 6$ seedlings (36\%), consistent with our previous report [20] (see Fig. 3). Exogenous pretreatment with $20 \mu \mathrm{M}$ SNP or SNAP increased the survival ratio of $c n g c 6$ seedlings greatly, to a value that was similar to that seen for wildtype seedlings (Fig. 2d), indicating that the addition of NO rescued the heat sensitivity of the mutant in the absence of CNGC6. Also, it slightly increased the survival ratio of wild-type seedlings (Fig. 2d). Based on these results, we reached the preliminary conclusion that NO is involved in CNGC6 signaling as a downstream factor.

\section{AtNOA1 and AtNIA2 overexpression in a cngc6 background improves thermotolerance}

We previously found that NO functions as a signal in thermotolerance using the mutants noa1 and nia1 nia2, which show heat sensitivity due to a deficiency in $\mathrm{NO}$ [10]. To further confirm the influence of CNGC6 on NO signaling under HS conditions, we obtained two AtNOA1overexpressing transgenic lines, cngc6/35S::NOA1-1 and cngc6/35S::NOA1-2, and two AtNIA2-overexpressing transgenic lines, cngc6/35S::NIA2-1 and cngc6/35S::NIA23 , and examined the effects of excess internal $\mathrm{NO}$ on CNGC6-deficient mutants under HS. The elevated expression of AtNOA1 and AtNIA2 was confirmed by real-time quantitative RT-PCR (RT-qPCR) (Figs. 3a, 4a).

DAF-FM fluorescence analysis revealed that AtNOA1 and AtNIA2 overexpression increased the internal NO levels in the transgenic lines under normal and HS conditions (Figs. 3, 4). At room temperature, no obvious phenotypic difference was observed between cngc6 and the transgenic plants. However, at high temperatures, AtNOA1 or AtNIA2 overexpression obviously increased the survival ratio of the corresponding transgenic lines compared to cngc6 (Figs. 3, 4).

These results show that the overexpression of AtNOA1 or AtNIA2 restored thermotolerance in a CNGC6-deficient mutant, providing genetic proof of the relationship between NO and CNGC6 in thermotolerance.

\section{Effects of HS on the thermotolerance of cngc6 noa1 double-mutant seedlings}

To further determine the roles of CNGC6 and NO in thermotolerance, we obtained the cngc6 noa1 double mutant by crossing, which was deficient in CNGC6 and 

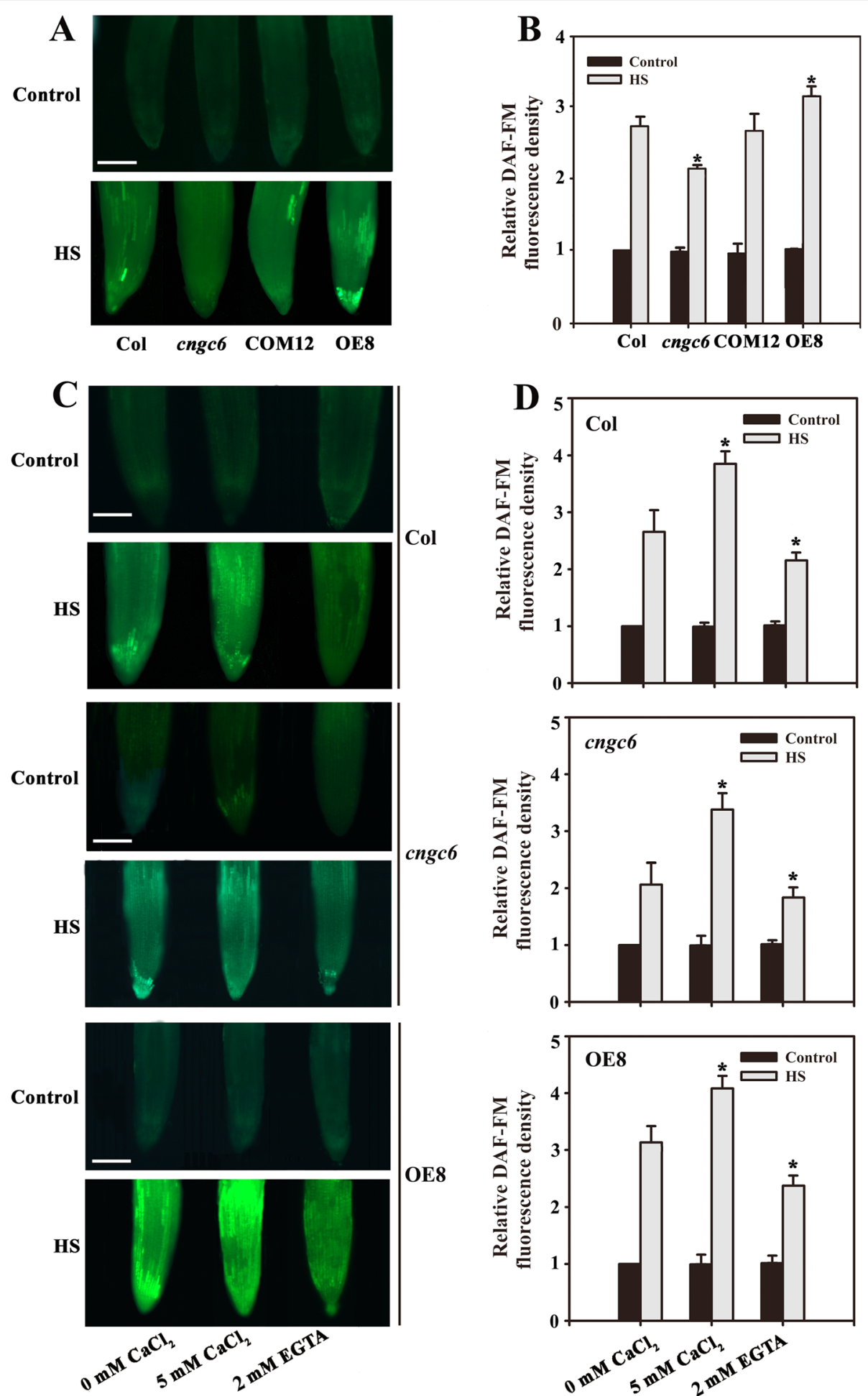

Fig. 1 Effects of $\mathrm{Ca}^{2+}$ on $\mathrm{NO}$ accumulation in Arabidopsis seedlings. (a) Eight-day-old wild-type, cngc6, COM12, and OE8 seedlings grown at $22^{\circ} \mathrm{C}$ were exposed to $45^{\circ} \mathrm{C}(\mathrm{HS})$ or maintained at $22^{\circ} \mathrm{C}$ (Control) for $60 \mathrm{~min}$. The NO levels in the seedlings were then examined by fluorescence microscopy using roots dyed with DAFFM DA. Bar $=100 \mu \mathrm{m}$. (b) Relative DAF-FM fluorescence densities in the roots. The data presented are the means \pm standard error (SE) of measurements taken from five independent experiments with at least ten roots for each treatment. ${ }^{*} P<0.05$ versus Col (Student's t-test). (c) Eight-day-old wild-type, cngc6, and OE8 seedlings were exposed to $45^{\circ} \mathrm{C}(\mathrm{HS})$ or maintained at $22^{\circ} \mathrm{C}$ (Control) for $60 \mathrm{~min}$. The $\mathrm{NO}$ levels in the plants were then examined by fluorescence microscopy using roots stained with DAF-FM DA. Bar $=100 \mu \mathrm{m}$. (d) The relative DAF-FM fluorescence densities in the roots. The data presented are the means \pm SE of measurements taken from five independent experiments with at least ten roots for each treatment. ${ }^{*} P<0.05$ versus $0 \mathrm{mM} \mathrm{CaCl}_{2}$ (Student's $t$-test) 


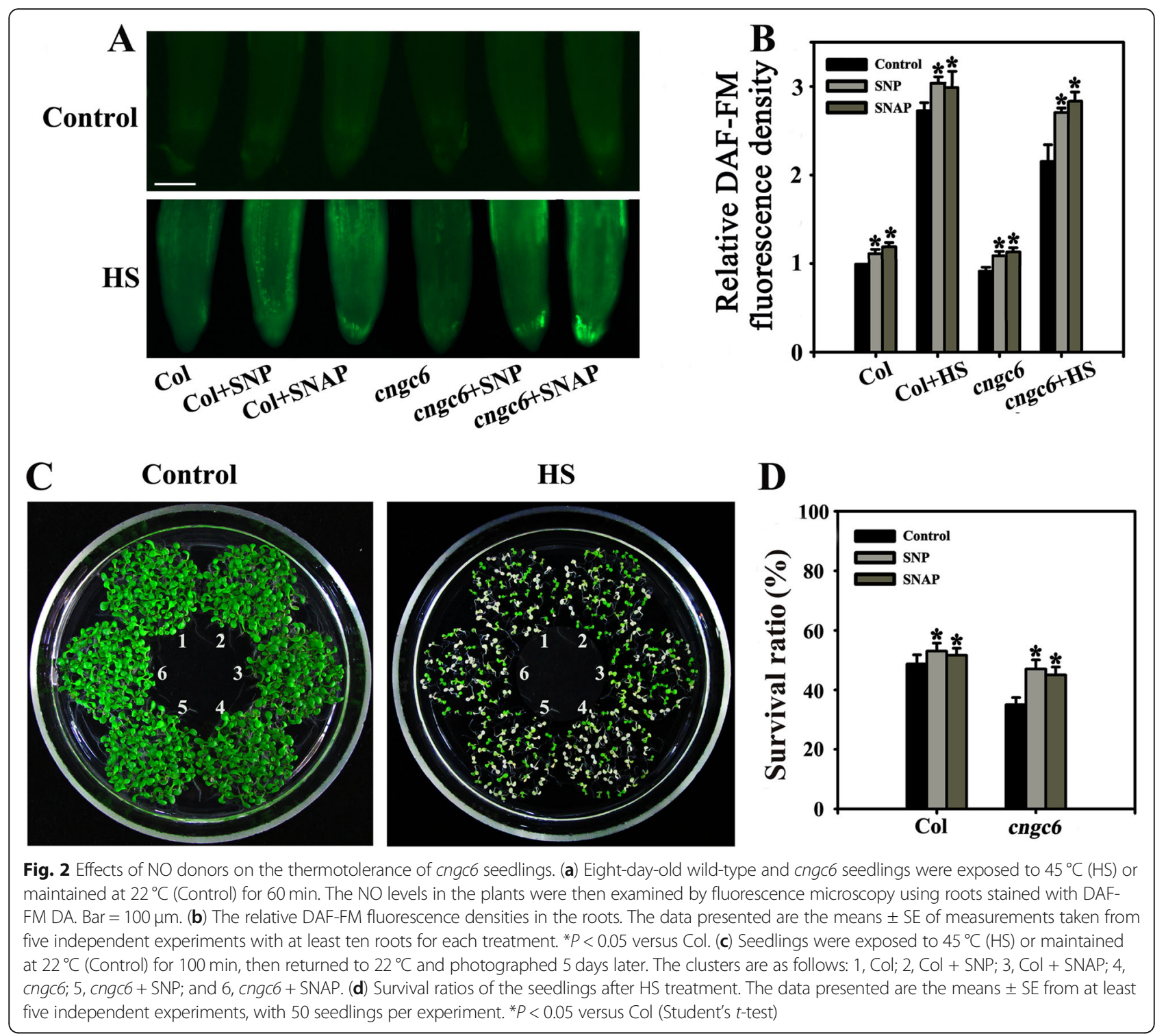

NOA1 transcription using RT-qPCR (Fig. 5a). Under normal and HS conditions, the NO level in the cngc6 noa1 seedlings was near to the value in the noal seedlings (Fig. 5b, c), indicating that the absence of CNGC6 did not obviously decrease $\mathrm{NO}$ accumulation in noa1 seedlings. Under normal conditions, cngc6 noa1 seedlings showed small and chlorotic, similar to noa1 seedlings (Fig. 5d, Control). Under HS conditions, the survival ratio of the cngc6 noa1 seedlings was close to that of noa1 seedlings (Fig. 5d, e), indicating that the absence of CNGC6 did not exacerbate the heat sensitivity of noal.

\section{Effects of CNGC6 via NO on AtHSP17.7 and AtHSP21 expression}

HSPs are important for all organisms to survive under acute stress by keeping proteostasis as molecular chaperones. To examine the underlying mechanism of CNGC6- and NO-induced thermotolerance in Arabidopsis, we next examined the effects of CNGC6 and NO on the accumulation of AtHSP17.7 and AtHSP21 in seedlings by Western blotting. Both of AtHSP17.7 and AtHSP21 were not detected at $22^{\circ} \mathrm{C}$ (Fig. 6a, b); however, the accumulation of both proteins was observed at $37^{\circ} \mathrm{C}$. The level of accumulation was lower in the mutants than in wild type (and lowest for cngc6 noa1), and it was strongly stimulated by $20 \mu \mathrm{M}$ SNP or SNAP. In addition, AtHSP17.7 and AtHSP21 accumulation was stimulated in cngc6/35S:: NOA1-1 and cngc6/35S::NIA2-1 plants compared with cngc6 (non-transformed background; Fig. 6c, d). In each of these experiments, tubulin was used to ensure equal sample loading.

These upon results indicate that application of NO donors and the overexpression of AtNOA1 or AtNIA2 stimulated HSPs expression in a cngc6 mutant, providing 


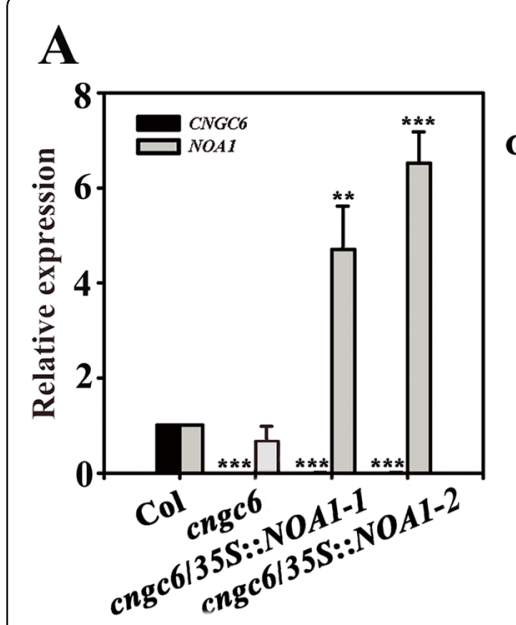

D

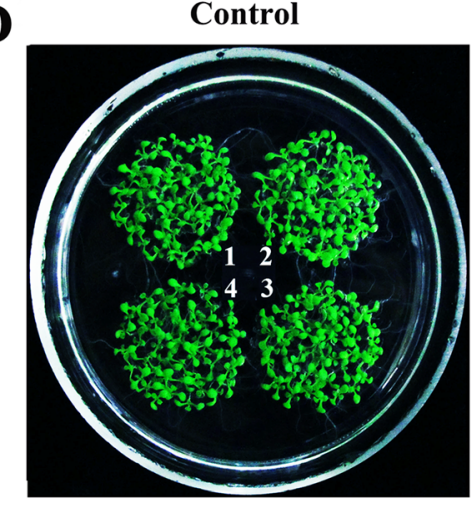

\section{B}

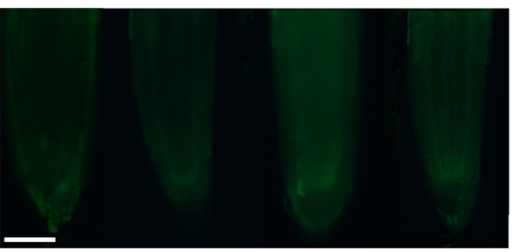

HS
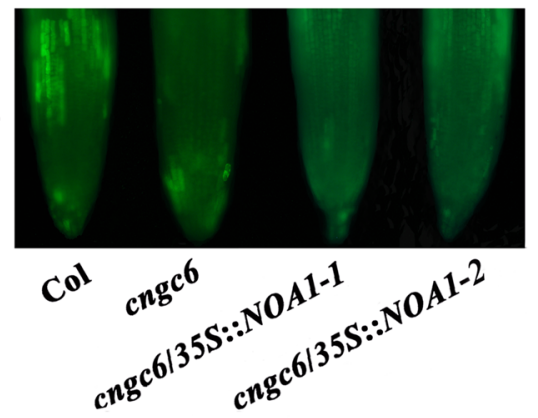

HS

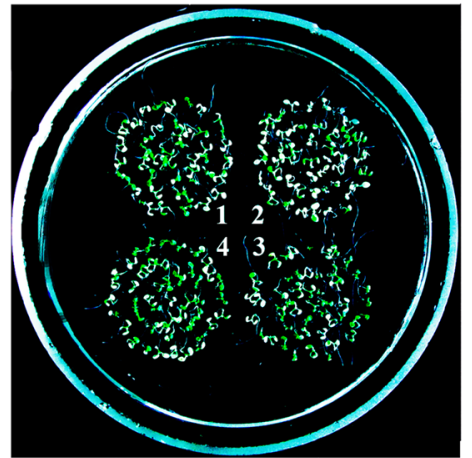

C

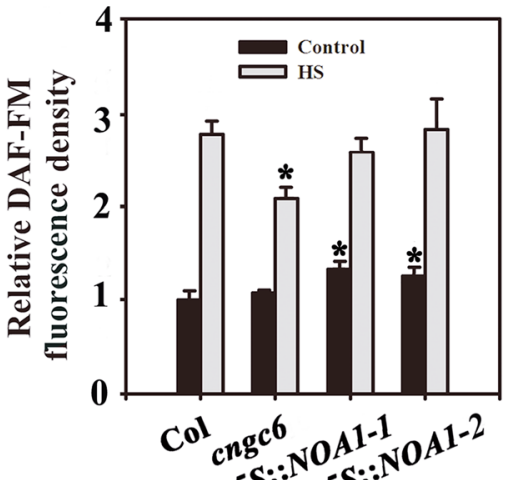

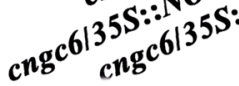

E

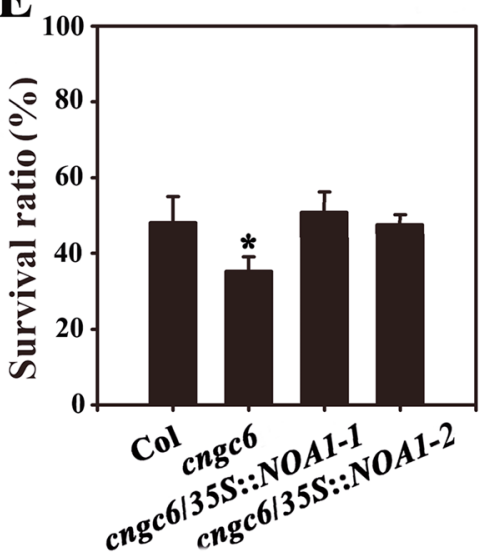

Fig. 3 Improved thermotolerance through AtNOA1 overexpression in a cngc6 background. (a) RT-qPCR analysis of AtCNGC6 and AtNOA1 transcription in wild-type, cngc6, cngc6/355::NOA1-1, and cngc6/355::NOA1-2 plants. The experiments were repeated three times with similar results. Each data point represents the mean \pm standard deviation $(S D ; n=3)$. Asterisks indicate a significant difference relative to Col (Student's $t$ test, ${ }^{* * P}<0.01$ and ${ }^{* * *} \mathrm{P}<0.001$ ). (b) Eight-day-old wild-type, cngc6, cngc6/355::NOA1-1, and cngc6/35S::NOA1-2 seedlings grown at $22^{\circ} \mathrm{C}$ were exposed to $45^{\circ} \mathrm{C}(\mathrm{HS})$ or maintained at $22^{\circ} \mathrm{C}$ (Control) for $60 \mathrm{~min}$. The NO levels in the plants were then examined by fluorescence microscopy using roots stained with DAF-FM DA. Bar $=100 \mu \mathrm{m}$. (c) The relative DAF-FM fluorescence densities in the roots. The data presented are the means $\pm \mathrm{SE}$ of measurements taken from five independent experiments with at least ten roots for each treatment. ${ }^{*} P<0.05$ versus Col. (d) Seedlings grown at $22^{\circ} \mathrm{C}$ were exposed to $45^{\circ} \mathrm{C}(\mathrm{HS})$ or maintained at $22^{\circ} \mathrm{C}$ (Control) for $100 \mathrm{~min}$, then returned to $22^{\circ} \mathrm{C}$ and photographed 5 days later. The clusters are as follows: 1, wild type; 2, cngc6; 3, cngc6/35S::NOA1-1; and 4, cngc6/35S::NOA1-2. (e) Survival ratios of the seedlings after HS treatment. The data presented are the means \pm SE of at least five independent experiments with 50 seedlings per experiment. ${ }^{*} \mathrm{P}<0.05$ versus Col (Student's t-test)

further evidence that NO acts downstream of CNGC6 in the HS pathway.

Effects of $\mathrm{NO}$ on the activity of $\mathrm{Ca}^{2+}$-permeable channel The above results provided evidence of the role of CNGC6 on the NO-mediated acquisition of thermotolerance in Arabidopsis seedlings. In plants, a specific role for NO in controlling $\mathrm{Ca}^{2+}$ homeostasis has also been reported [24].

To determine whether $\mathrm{NO}$ affects the function of heatresponsive $\mathrm{Ca}^{2+}$-permeable channels under HS conditions, we examined the effects of endogenous $\mathrm{NO}$ on the activity of CNCG6 in the PM of Arabidopsis root protoplasts with the whole-cell patch-clamp technique [20]. Under normal conditions, the $\mathrm{Ca}^{2+}$ current in cngc6 $(-36 \mathrm{pA})$ was lower than that in wild type $(-118 \mathrm{pA})$ at $-200 \mathrm{mV}$. Under $\mathrm{HS}$ at $37^{\circ} \mathrm{C}$, the inward $\mathrm{Ca}^{2+}$ current was greatly increased to $369 \mathrm{pA}$ in wild type within $1 \mathrm{~min}$, whereas only a slight increase (to $-90 \mathrm{pA}$ ) was observed in cngc6 (Fig. 7a, b), consistent with our previous report [20]. In noal mutant with low internal NO levels, the $\mathrm{Ca}^{2+}$ currents showed no obvious difference with those in wild type under normal and HS conditions (Fig. 7c). In two transgenic lines with high internal NO levels, cngc6/35S::NOA1-1 and cngc6/35S::NIA2-1, the $\mathrm{Ca}^{2+}$ currents were similar to those of $c n g c 6$ (non-transgenic 


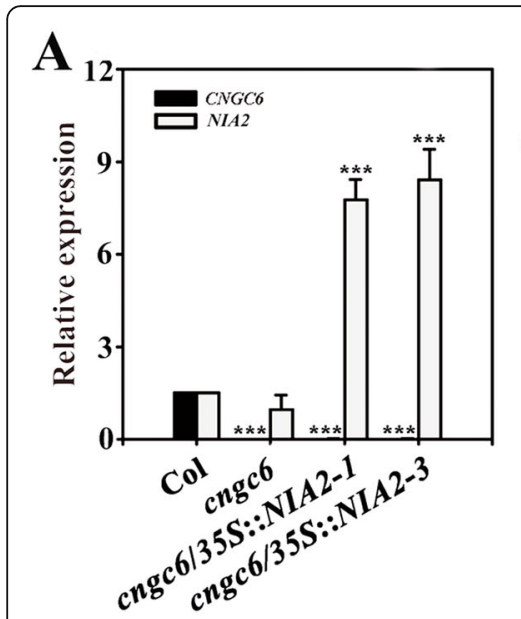

D

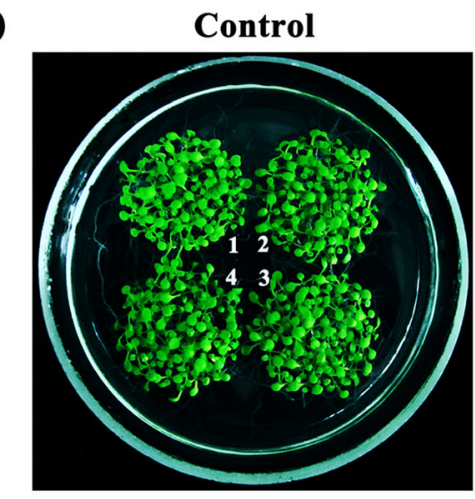

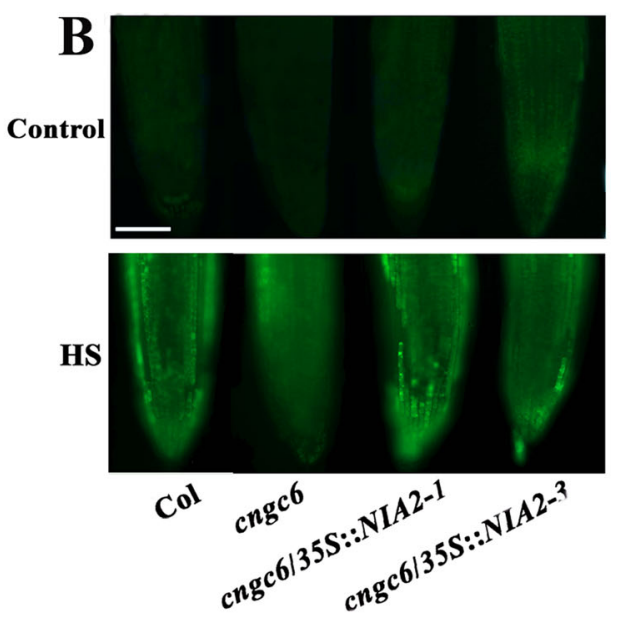

HS

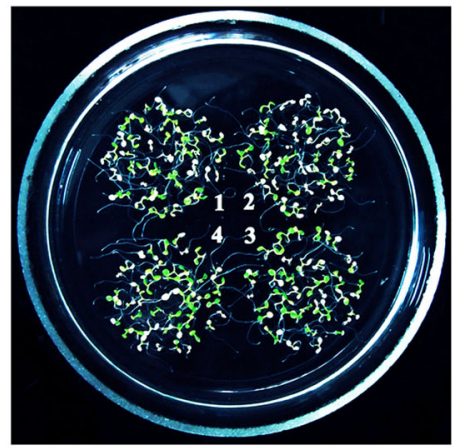

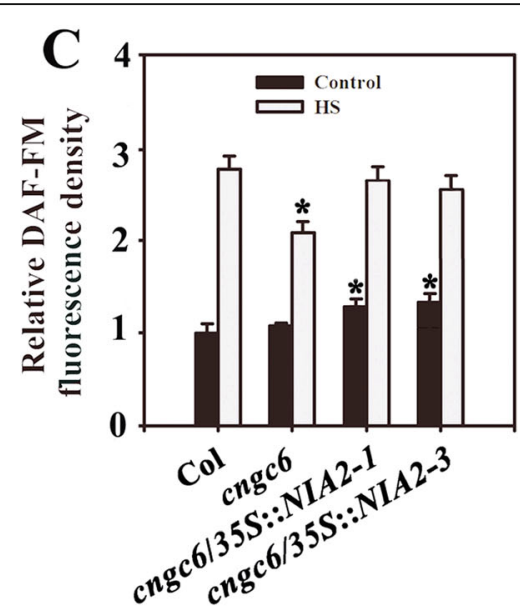

$\mathbf{E}$

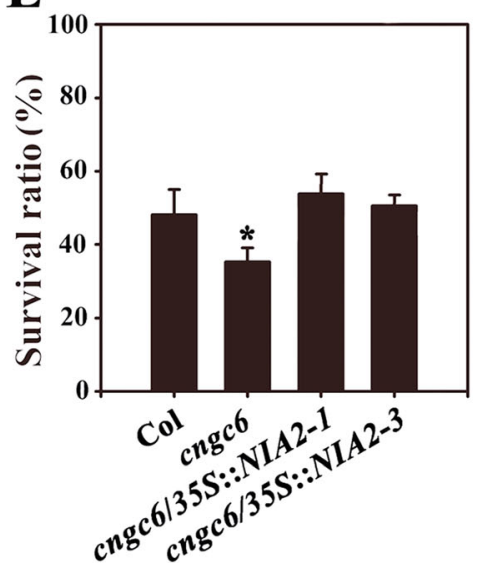

Fig. 4 Improved thermotolerance through AtNIA2 overexpression in a cngc6 background. (a) RT-qPCR analysis of AtCNGC6 and AtNIA2 transcription in wild-type, cngc6, cngc6/35S::NIA2-1, and cngc6/35S::NIA2-3 plants. The experiments were repeated three times with similar results. Each data point represents the mean $\pm S D(n=3)$. Asterisks indicate a significant difference relative to Col (Student's $t$-test, $\left.{ }^{* * *} P<0.001\right)$. (b) Eightday-old wild-type, cngc6, cngc6/355::NIA2-1, and cngc6/355::NIA2-3 seedlings grown at $22^{\circ} \mathrm{C}$ were exposed to $45^{\circ} \mathrm{C}$ (HS) or maintained at $22^{\circ} \mathrm{C}$ (Control) for $60 \mathrm{~min}$. The NO levels in the plants were then examined by fluorescence microscopy using roots stained with DAF-FM DA. Bar $=$ $100 \mu \mathrm{m}$. (c) The relative DAF-FM fluorescence densities in the roots. The data presented are the means \pm SE of measurements taken from five independent experiments with at least ten roots for each treatment. ${ }^{*} P<0.05$ versus Col (Student's $t$-test). (d) Seedlings grown at $22^{\circ} \mathrm{C}$ were exposed to $45^{\circ} \mathrm{C}$ (HS) or maintained at $22^{\circ} \mathrm{C}$ (Control) for $100 \mathrm{~min}$, then returned to $22^{\circ} \mathrm{C}$ and photographed 5 days later. The clusters are as follows: 1, wild type; 2, cngc6; 3, cngc6/35S::NIA2-1; and 4, cngc6/355::NIA2-3. (e) Survival ratios of the seedlings after HS treatment. The data presented are the means \pm SE of at least five independent experiments with 50 seedlings per experiment. ${ }^{*} P<0.05$ versus Col (Student's $t$-test)

background) under normal and HS conditions (Fig. 7d, e). These results were proved by the determination of $\left[\mathrm{Ca}^{2+}\right]_{\mathrm{cyt}}$ level using a $\mathrm{Ca}^{2+}$ sensor protein aequorin (Additional file 1 : Figure S1), suggesting that NO had no obvious effect on $\mathrm{Ca}^{2+}$ channel activity.

\section{Discussion}

The relationships among $\mathrm{CNGC6}, \mathrm{Ca}^{2+}$, and NO accumulation under HS conditions in Arabidopsis seedlings

Exposure to high temperatures usually results in increased $\left[\mathrm{Ca}^{2+}\right]_{\mathrm{cyt}}$ and the production of $\mathrm{NO}$ in plant cells; both of $\mathrm{Ca}^{2+}$ and NO play important roles in plant resistance to heat stress $[10,26,29]$. What is the relationship between
$\mathrm{Ca}^{2+}$ and NO signaling pathways in heat tolerance? In this study, we obtained evidence that CNGC6, a heat-activated $\mathrm{Ca}^{2+}$-permeable channel, induces NO production so as to regulate the accumulation of HSPs to promote thermotolerance in Arabidopsis.

$\mathrm{NO}$, as an important messenger in multiple biological processes in plants, is induced by numerous components to mediate resistance responses. We previously found that $\mathrm{NO}$ functions as a signal in plant thermotolerance [10]. We subsequently demonstrated that $\mathrm{H}_{2} \mathrm{O}_{2}$ functions as a second messenger in the induction of thermotolerance through $\mathrm{NO}$ [12]. $\mathrm{H}_{2} \mathrm{O}_{2}$ was previously reported to be involved in increasing intracellular levels of free $\mathrm{Ca}^{2+}$ [30]. Recently, several 


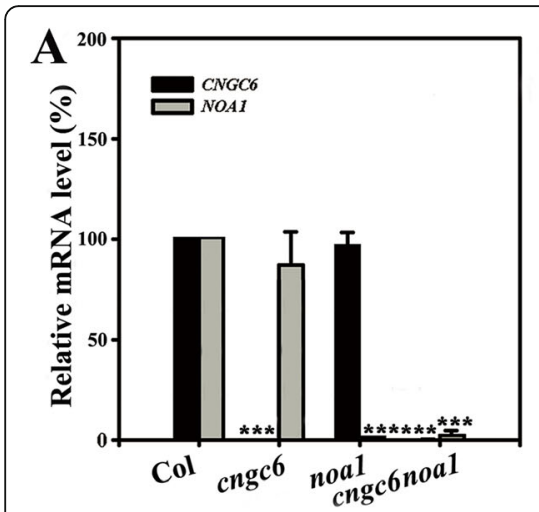

D

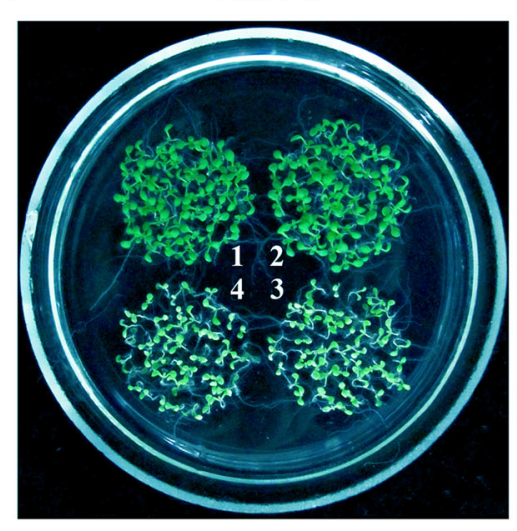

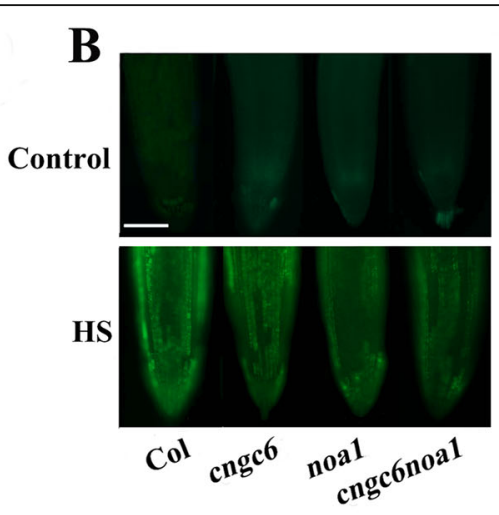

HS

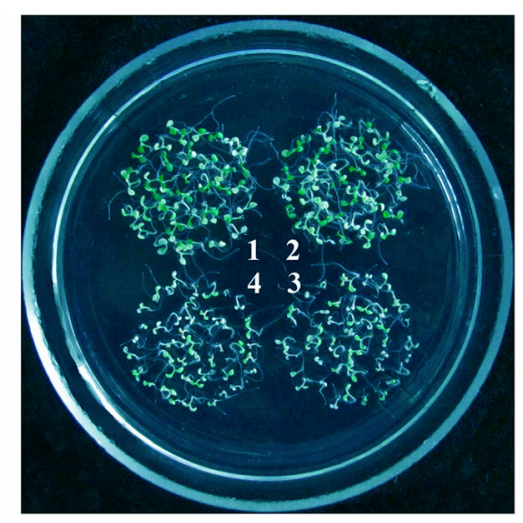

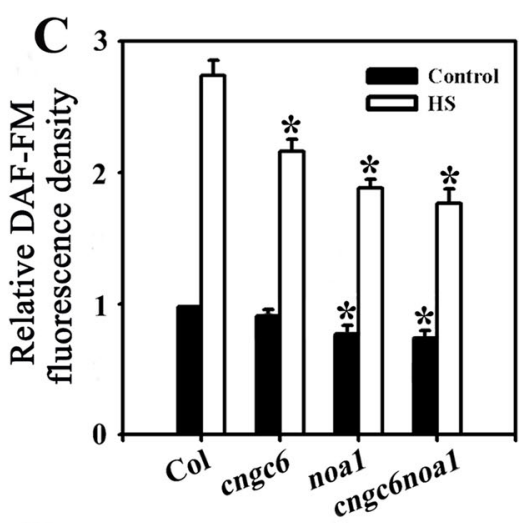

$\mathbf{E}$

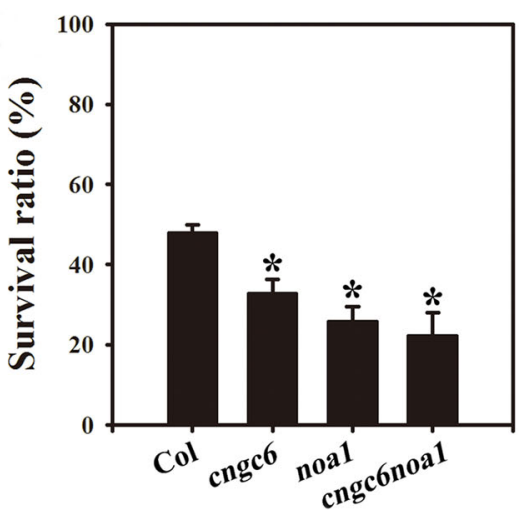

Fig. 5 Survival status of the cngc6 noa1 double mutant. (a) RT-qPCR analysis of CNGC6 and NOA1 transcription in wild-type, cngc6, noa1, and cngc6 noal seedlings. The experiments were repeated three times with similar results. Each data point represents the mean \pm SD $(n=3)$. Asterisks indicate a significant difference relative to Col. ${ }^{* * *} \mathrm{P}<0.001$ (Student's t-test). (b) Eight-day-old wild-type, cngc6, noa1, and cngc6 noal seedlings grown at $22^{\circ} \mathrm{C}$ were exposed to $45^{\circ} \mathrm{C}(\mathrm{HS})$ or maintained at $22^{\circ} \mathrm{C}$ (Control) for $60 \mathrm{~min}$. The NO levels in the seedlings were then examined by fluorescence microscopy using roots stained with DAF-FM DA. Bar $=100 \mu \mathrm{m}$. (c) Relative DAF-FM fluorescence densities in the roots. The data presented are the means \pm standard error (SE) of measurements taken from five independent experiments with at least ten roots for each treatment. ${ }^{*} P<0.05$ versus $\mathrm{Col}$ (Student's $t$-test). (d) Eight-day-old seedlings grown at $22^{\circ} \mathrm{C}$ were exposed to $45^{\circ} \mathrm{C}$ (HS) or maintained at $22^{\circ} \mathrm{C}$ (Control) for $100 \mathrm{~min}$, then returned to $22^{\circ} \mathrm{C}$ and photographed 5 days later. The clusters are as follows: 1, wild type; 2 , cngc6; 3, noa 1; and 4, cngc6 noa1. (e) Survival ratios of the seedlings after HS treatment. The data presented are the means \pm SE of at least five independent experiments with 50 seedlings per experiment. ${ }^{*} \mathrm{P}<0.05$ (Student's $t$-test)

studies have highlighted the role of $\mathrm{Ca}^{2+}$ in initiating NO production in plants $[25,31]$. Thus, we deduced that there should be a close relationship between $\mathrm{Ca}^{2+}$ and $\mathrm{NO}$ in HS signaling.

CNGCs affect various biological processes by regulating the influx and efflux of ions. We identified a heatand cAMP-activated $\mathrm{PM} \mathrm{Ca}^{2+}$ channel, CNGC6, which is involved in conducting $\mathrm{Ca}^{2+}$ into the cytoplasm; in that study, a T-DNA insertion mutant, cncg6, exhibited a lower $\mathrm{Ca}^{2+}$ current than wild type [20]. Moreover, the inward $\mathrm{Ca}^{2+}$ currents in COM12 and OE8 were higher than that in cngc6 depending on the CNGC6 expression level under HS conditions [20], suggesting that CNGC6 mediates the influx of $\mathrm{Ca}^{2+}$ into cells. Therefore, we utilized $c n g c 6$ and the above two transgenic lines to investigate the relationship between CNGC6 and NO under HS conditions.
First, we examined NO accumulation using the fluorescent probe DAF-FM DA under HS conditions. Under normal growth conditions, the NO levels of wild-type, cngc6, COM12, and OE8 seedlings were relatively stable. However, high temperature exposure stimulated NO accumulation in these seedlings according to their CNGC6 expression levels (Fig. 1a, b), suggesting a significant role for CNGC6 in thermotolerance via the regulation of NO accumulation.

Due to the biological activity of CNCG6 in HS-treated plants, we examined the effect of $\mathrm{Ca}^{2+}$ on NO accumulation in wild-type, cngc6 and OE8 plants. Our experiments show that $\mathrm{Ca}^{2+}$ stimulated the accumulation of $\mathrm{NO}$ in these seedlings under HS conditions. However, the $\mathrm{Ca}^{2+}$ chelator EGTA obviously inhibited NO accumulation in wild-type and OE8 seedlings (Fig. 1c, d), suggesting that CNGC6-mediated free $\mathrm{Ca}^{2+}$ is a key 
Control

A

C

D cngc6/35S:NOA1-1

$\mathbf{E}$

cngc6/35S::NLA2-1

B

cngc6

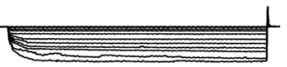

noa1
HS
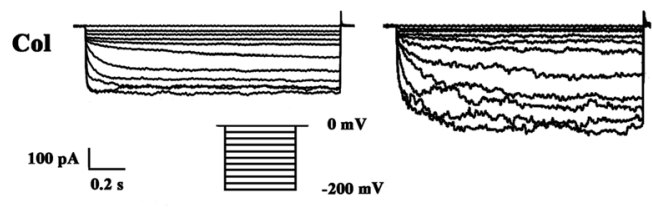

$-200 \mathrm{mV}$
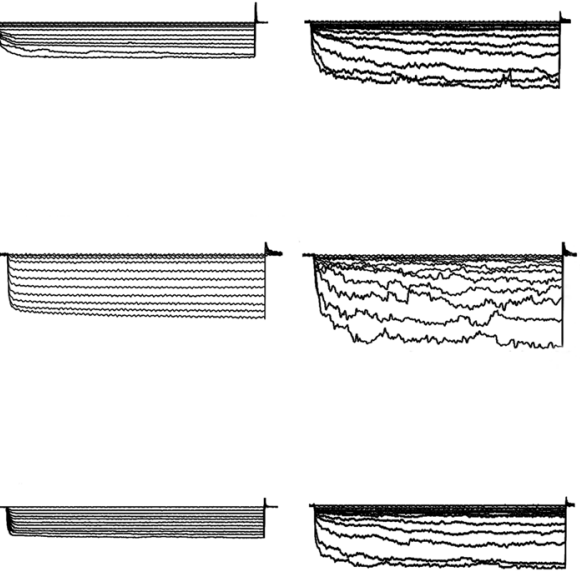

Fig. 6 Effects of CNGC6 via NO on AtHSP17.7 and AtHSP21 expression. (a-d) Ten-day-old seedlings grown at $22^{\circ} \mathrm{C}$ were exposed to $37^{\circ} \mathrm{C}$ (HS) or maintained at $22^{\circ} \mathrm{C}$ (Control) for $2 \mathrm{~h}$. Total protein was then extracted, separated by SDS-PAGE, and analyzed by Western blotting. Tubulin was used as an internal control. Three independent experiments were carried out; the results indicate similar trends in protein accumulation. The numbers below each lane represent the relative intensity of each signal

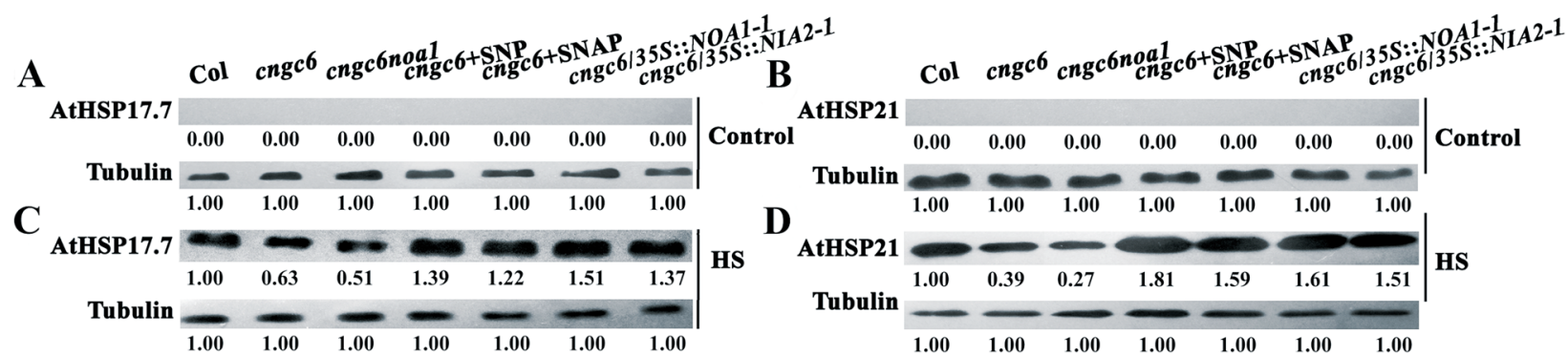

Fig. 7 Patch-clamp analysis of $\mathrm{Ca}^{2+}$-permeable channels in wild-type, cngc6, noa1, cngc6/35S::NOA1-1, and cngc6/35S::NIA2-1 seedlings. The $\mathrm{Ca}^{2+}$ current before $\mathrm{HS}$ (at $22^{\circ} \mathrm{C}$, control) and after HS (at $37^{\circ} \mathrm{C}, \mathrm{HS}$ ) was compared in the root cell protoplasts of 10 -day-old wild-type (a), cngc6 (b), noal (c), cngc6/35S::NOA1-1 (d) and cngc6/355::NIA2-1 (e) plants. The Ca ${ }^{2+}$ current was recorded by step voltage clamp. Each trace is a representative current from six protoplasts. Currents in the protoplasts are shown in the left and middle columns, respectively. The $I-V$ curve is shown in the right column (mean $\pm \mathrm{SD}, \mathrm{n}=6$ ) 
element in promoting NO signaling. Thus, we propose that CNGC6 regulates internal NO levels via free $\mathrm{Ca}^{2+}$ under HS conditions.

\section{Effects of NO and CNGC6 on thermotolerance in Arabidopsis seedlings}

To clarify the effects of NO and CNGC6 on heat tolerance, we examined the effects of $\mathrm{NO}$ on the survival of cngc6 plants under HS conditions. A moderate concentration $(20 \mu \mathrm{M})$ of two NO donors, SNP and SNAP, elevated the internal NO level and the survival ratio of HS-treated cngc6 seedlings (Fig. 2). The overexpression of two NO synthesis-related enzymes, NOA1 and NIA2, enhanced the internal $\mathrm{NO}$ level and the survival ratio of their transgenic lines, respectively, compared to cngc6 (non-transgenic background) under HS conditions (Figs. 3, 4). These results indicate that a rise in internal $\mathrm{NO}$ rescued the heat susceptibility of the plants due to the removal of CNGC6.

Finally, we obtained the double mutant cngc6 noa1, which exhibited a phenotype similar to that of noa1 under normal growth or HS conditions (Fig. 5), indicating that deficiencies in both noal and CNGC6 do not potentiate the heat susceptibility caused by a deficiency in noa1 alone.

The HS response is mediated via a process in which HSP expression is induced [1]. To confirm the relationship between CNGC6 and NO in the HS signaling pathway, we examined the effects of CNGC6 and NO on HSP expression under HS conditions. HSP genes are classified based on their molecular masses, such as HSP100, HSP90, HSP70, HSP60, and small HSPs. Among them, the small HSPs are the most important ones due to their crucial roles in plant survival under HS conditions [32]. Herein, two small HSPs, HSP17.7 and HSP21, were used to confirm whether CNGC6 through NO promotes HSP expression in plant thermotolerance. Western blotting revealed that under HS conditions, the reduced CNGC6 level in cngc6 inhibited the expression of AtHSP17.7 and AtHSP21. On the contrary, NO donors and NOA1 and NIA2 overexpression in cngc6 mutant increased the expression of AtHSP17.7 and AtHSP21 (Fig. 6), indicating that CNGC6 stimulates HSP expression through NO.

Collectively, our data provide physiological, pharmacological and biochemical proof of the existence of a HS signaling pathway in which $\mathrm{NO}$ acts as a downstream partner of CNGC6 to confer thermotolerance.

\section{Effects of $\mathrm{NO}$ on $\mathrm{Ca}^{2+}$ fluxes in thermotolerance in Arabidopsis seedlings}

NO-induced cGMP stimulates the synthesis of the $\mathrm{NAD}^{+}$metabolite cADPR, which is a potent $\mathrm{Ca}^{2+}$-mobilizing agent that binds to intracellular $\mathrm{Ca}^{2+}$ channels and activates the release of $\mathrm{Ca}^{2+}$ in tobacco (Nicotiana tabacum) [33]. In addition, a specific role for NO in elevating the availability of intracellular and extracellular $\mathrm{Ca}^{2+}$ pools was assumed during auxin-induced adventitious root formation in cucumber (Cucumis sativus) [34]. Accordingly, we wondered whether $\mathrm{NO}$ alters $\mathrm{Ca}^{2+}$ fluxes to affect thermotolerance.

A significant increase in $\left[\mathrm{Ca}^{2+}\right]_{\mathrm{cyt}}$ was observed in response to a single temperature increase from 22 to $37^{\circ} \mathrm{C}$ in wild-type plants (Fig. 7). However, the current was obviously inhibited in $c n g c 6$, cngc6/35S::NOA1-1, and cngc6/35S::NIA2-1 plants but not clearly altered in noa1 plants (Fig. 7), indicating no clear effect of $\mathrm{NO}$ on $\mathrm{Ca}^{2+}$ permeable channel activity. These data, in combination with the results shown in Figs. 2, 3, 4 and 5, suggest that the HS-induced change in $\left[\mathrm{Ca}^{2+}\right]_{\text {cyt }}$ unidirectionally influences NO signaling in plants. A plausible explanation for these results is that supplementation with $\mathrm{NO}$, a downstream molecule, restored the heat-sensitive status of the CNGC6-deficient seedlings (Figs. 2, 3, 4 and 5) but could not activate the heat-responsive activity of CNGC6 (Fig. 7).

However, there was a strange phenomenon that in the cngc6 mutant, NO production was also stimulated under HS, which can be slightly inhibited by EGTA (Fig. 1). This should be due to the action of phosphoinositidespecific phospholipase C9 [35] and phosphoinositidespecific phospholipase C3 [36] in mediating the elevation of $\left[\mathrm{Ca}^{2+}\right]_{\mathrm{cyt}}$ through intracellular calcium pool under HS.

\section{Conclusion}

To our knowledge, these data provide the evidence that the HS-responsive $\mathrm{Ca}^{2+}$-permeable channel CNGC6 participates in the induction of HS signaling through NO. We previously proposed a model for HS signaling in which the HS signal was identified by an unknown receptor, leading to an increased $\mathrm{H}_{2} \mathrm{O}_{2}$ level, which directly stimulated $\mathrm{NO}$ accumulation and activated AtCaM3 to initiate plant adaptation to high temperatures [12]. Additionally, a feedback inhibition was proposed to exist between $\mathrm{NO}$ and $\mathrm{H}_{2} \mathrm{O}_{2}$ in the $\mathrm{HS}$ pathway in Arabidopsis seedlings [14]. In this study, CNGC6 was found to act upstream of NO through free $\mathrm{Ca}^{2+}$ in the response of plants to $\mathrm{HS} . \mathrm{H}_{2} \mathrm{O}_{2}$ application was also shown to increase the intracellular level of free $\mathrm{Ca}^{2+}[37] . \mathrm{Ca}^{2+}$ and AtCaM3 are involved in the expression of HSP genes in Arabidopsis [38]. CaM, upon binding to $\mathrm{Ca}^{2+}$, attaches to specific target proteins, altering their functions as part of a HS-responsive $\mathrm{Ca}^{2+}$ signal transduction pathway; demonstrated targets include CaM-binding protein kinase 3 [39] and PP7 [40]. These findings suggest that complicated relationship occurs among $\mathrm{H}_{2} \mathrm{O}_{2}, \mathrm{NO}, \mathrm{Ca}^{2+}$ channels, and the $\mathrm{Ca}^{2+}$ / CaM-dependent activation of target proteins in the HS pathway (Fig. 8). 


\section{Methods}

\section{Plant materials and growth conditions}

The wild-type and mutant Arabidopsis were Col-0 ecotype. The noa1 seeds were provided by Dr. Nigel M. Crawford (University of California, San Diego, CA). 35S::NIA2-1 and 35S::NIA2-3 seeds were obtained from Dr. Chun-Peng Song (Henan University, Kaifeng, China). The double mutant cngc6 noa1 and transgenic lines cngc6/35S::NIA2-1 and $c n g c 6 / 35 S:$ NIA2-3 were obtained by crossing, while the transgenic lines cngc6/35S::NOA1-1 and cngc6/35S:: NOA1-2 were obtained by the floral dip method.

The Arabidopsis seeds were surface-sterilized in $2 \%(\mathrm{v} / \mathrm{v})$ sodium hypochlorite for $1 \mathrm{~min}$ and then washed thoroughly with water. The sterilized seeds were placed on Murashige and Skoog (MS) medium containing 3\% sucrose and 0.7\% agar and kept at $4{ }^{\circ} \mathrm{C}$ in the dark for $48 \mathrm{~h}$. The plants were then transferred to a growth chamber set at $22^{\circ} \mathrm{C}$ and $120 \mu \mathrm{mol} \mathrm{m}^{-2} \mathrm{~s}^{-1}$ on a 16 -h 16 -h daily light period.

For chemical treatment, $2 \mathrm{ml}$ of SNP or SNAP $(20 \mu \mathrm{M}$ each) (Sigma-Aldrich, St. Louis, MO) were sprinkled onto the leaf surfaces of 8-day-old seedlings after filter

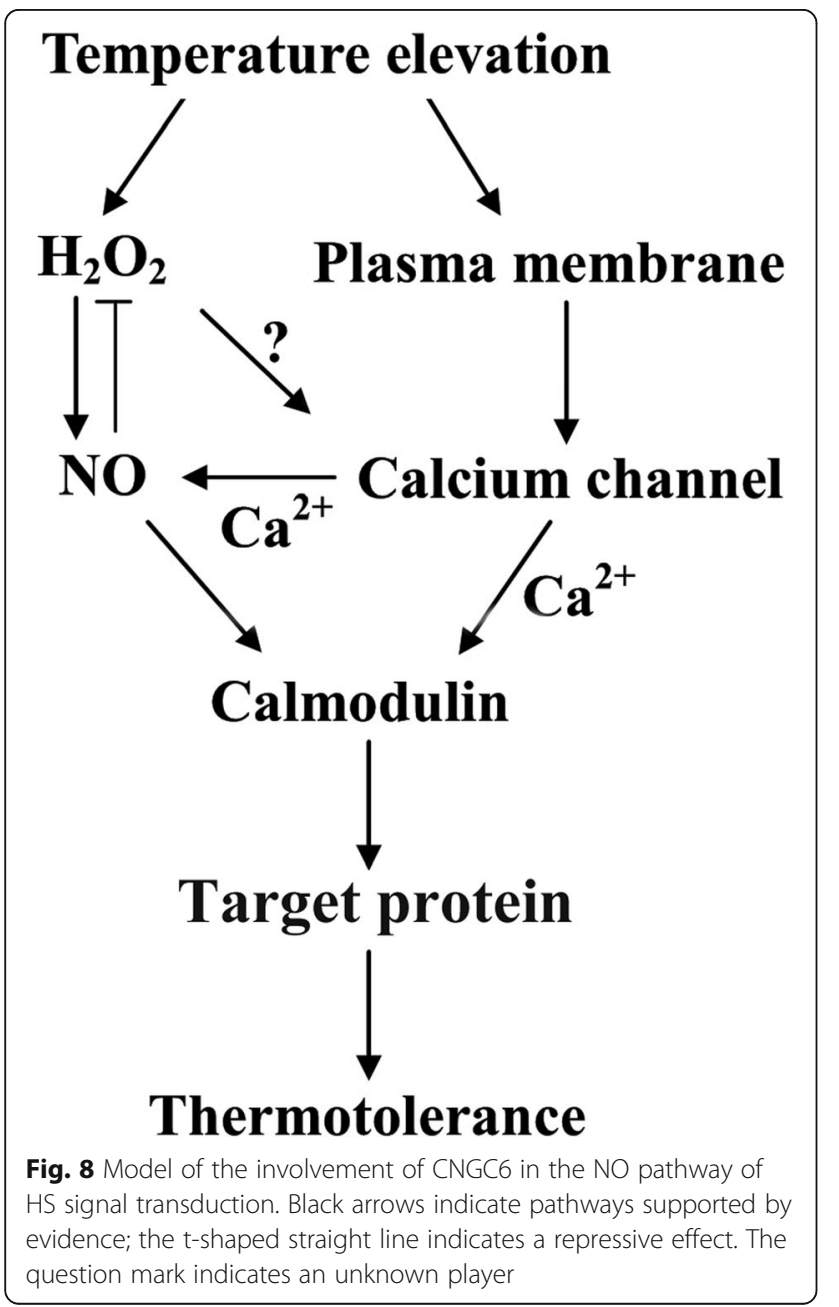

sterilization for $48 \mathrm{~h}$. Water was used as a substitute for control seedlings. After $8 \mathrm{~h}$ of pretreatment, the seedlings were subjected to HS conditions [12]. In addition, $5 \mathrm{mM} \mathrm{CaCl}_{2}$ or $2 \mathrm{mM}$ EGTA was used to pretreat wildtype, cngc6, and OE8 seeds for $30 \mathrm{~min}$ in the fluorescence experiment, with ultrapure water as the control.

\section{Thermotolerance testing}

Eight-day-old seedlings, grown at $22^{\circ} \mathrm{C}$, were incubated in sterilized $5 \mathrm{mM} \mathrm{CaCl} 2$ at $37^{\circ} \mathrm{C}$ for $30 \mathrm{~min}$, returned to $22^{\circ} \mathrm{C}$ for $2 \mathrm{~h}$, then challenged at $45^{\circ} \mathrm{C}$ for $100 \mathrm{~min}$, and finally returned $22^{\circ} \mathrm{C}$ for 5 days of recovery [26]. Those seedlings being still green and continuing to produce new leaves were registered as survivors. For Western blotting, 10-day-old seedlings were kept at $37^{\circ} \mathrm{C}$ for $2 \mathrm{~h}$ and collected for the analyses of HSP accumulation.

All the experiments were repeated for at least three times, and three independent biological replicates for each time.

\section{Fluorescence microscopy}

$\mathrm{NO}$ was visualized using the specific fluorescent probe DAF-FM DA (Sigma-Aldrich) as described previously [5] with some modifications. Wild-type and mutant seedlings were incubated in $1 \mathrm{ml}$ of liquid MS medium (pH 5.8) with $10 \mu \mathrm{M}$ DAF-FM DA for $20 \mathrm{~min}$. Then, the roots were washed three times for $15 \mathrm{~min}$ each in liquid MS medium prior to visualization with a fluorescence microscope (Eclipse TE 200, Nikon, Tokyo, Japan). The signal intensities were calculated using MetaMorph (Molecular Devices, Sunnyvale, CA).

\section{Vector construction and the generation of transgenic plants}

To obtain AtNOA1-YFP for the production of plants overexpressing AtNOA1 in a cngc6 background, AtNOA1 complementary DNA (cDNA) was amplified by reverse transcription-polymerase chain reaction (RT-PCR) with the primers NOA1F1 (5' -CACCATGGCGCTACGAACACTC TCAA-3') and NOA1F2 (5'-AAAGTACCATTTGGGTCT TACT-3') (the underlined sequence in NOA1F1 was used to link to pENTR/SD/D-TOPO within this reaction chain). The product was cloned in the sense orientation into pENTR/SD/D-TOPO and then into pEarleyGate 101 using Gateway LR Recombinase (Invitrogen Corp., Carlsbad, CA) to generate $35 S:$ AtNOA1-YFP.

The transformation of this construct into Arabidopsis (cngc6) was performed according to the floral dip method [41] with Agrobacterium tumefaciens (strain GV3101). Transformants were screened on plates containing $15 \mathrm{mg} \mathrm{l}^{-1}$ of Basta. Homozygous T3 transgenic lines were selected for further analysis. 


\section{RT-qPCR analysis}

Total RNA (500 ng) was isolated from 10-day-old seedlings at $37^{\circ} \mathrm{C}$ for $1 \mathrm{~h}$ with a PrimeScript RT Reagent Kit (Takara Bio Inc., Otsu, Japan) for first-stand cDNA synthesis as the manufacturer's instructions. The program was as follows: initial polymerase activation for $10 \mathrm{~s}$ at $95^{\circ} \mathrm{C}$ followed by 40 cycles of $95^{\circ} \mathrm{C}$ for $5 \mathrm{~s}$ and $60^{\circ} \mathrm{C}$ for $31 \mathrm{~s}$. The reactions were performed using an ABI Prism 7000 sequence detection system (Applied Biosystems, Foster City, CA) with SYBR Premix Ex Taq (Takara Bio Inc.). Primer pairs were designed using Primer Express (Applied Biosystems). Detailed primer sequences are shown in Additional file 1: Table S1.

\section{Western blot analysis}

Ten-day-old seedlings were kept at $37{ }^{\circ} \mathrm{C}$ for $2 \mathrm{~h}$ and then ground in liquid nitrogen. Total protein was extracted with an extraction buffer (10 mM HEPES, $\mathrm{pH}$ 7.9, containing $0.4 \mathrm{M} \mathrm{NaCl}, 0.5 \mathrm{mM}$ dithiothreitol, 0.1 $\mathrm{mM}$ EDTA, $5 \%$ glycerol, and $0.5 \mathrm{mM}$ phenylmethanesulfonyl fluoride), and the extracts were purified by centrifugation at $14,000 \times g$ for $20 \mathrm{~min}$ at $4{ }^{\circ} \mathrm{C}$. The supernatants were transferred to fresh tubes, and the protein content was measured as the description of Bradford [42]. Total proteins $(50 \mu \mathrm{g})$ were analyzed by western blotting as described previously [12].

\section{Preparation of protoplasts and electrophysiology analysis} Protoplasts were isolated as described previously [43] from $1 \mathrm{~cm}$ long of root tips of Arabidopsis seedlings cultivated vertically at $22^{\circ} \mathrm{C}$ for $6-7$ days. Whole-cell voltage patch-clamping was carried out as described previously $[20,44]$.

In vivo reconstitution of aequorin and $\mathrm{Ca}^{2+}$ measurement In vivo reconstitution of the aequorin was conducted according to Gao's method [20]. The $\left[\mathrm{Ca}^{2+}\right]_{\text {cyt }}$ level was obtained by calculating the $\mathrm{pCa}$ with the equation as described previously [45].

\section{Additional files}

Additional file 1: Figure S1. $\left[\mathrm{Ca}^{2+}\right]_{\mathrm{cyt}}$ analysis using $\mathrm{Ca}^{2+}$ sensor protein aequorin in wild-type, cngc6, noa1, cngc6/355::NOA1-1, and cngc6/ 355::NIA2-1 seedlings. Table S1. Primers used for real-time quantitative RT-PCR. (PDF $91 \mathrm{~kb})$

\footnotetext{
Abbreviations

$\left[\mathrm{Ca}^{2+}\right]_{\mathrm{cyt}}$ : Cytosolic $\mathrm{Ca}^{2+} ; \mathrm{Ca}^{2+}$ : Calcium ions; CaM3: Calmodulin3; CDNA: Complementary DNA; CNGC: Cyclic nucleotide-gated cation channels;

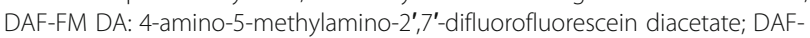
FM: 4-amino-5-methylamino-2',7'-difluorofluorescein; $\mathrm{H}_{2} \mathrm{O}_{2}$ : Hydrogen peroxide; HS: Heat shock; HSP: Heat shock protein; MS: Murashige and skoog; NIA1: Nitrate reductase 1; NIA2: Nitrate reductase 2; NO: Nitric oxide; NOA1: Nitric oxide-associated protein 1; NOS: NO synthase; NR: Nitrate reductase; PM: Plasma membrane; RT-PCR: Reverse transcription-polymerase chain reaction; RT-qPCR: Real-time quantitative RT-PCR; SDS-PAGE: Sodium
}

dodecyl sulfate polyacrylamide gel electrophoresis; SNAP: S-nitroso-Nacetylpenicillamine; SNP: sodium nitroprusside

\section{Acknowledgements}

We thank Drs. Nigel M. Crawford (University of California, San Diego, CA) and Chun-Peng Song (Henan University, Kaifeng, China) for providing the seeds used in this research.

\section{Authors' contributions}

$B L$ and $L Z$ designed the research; $X P$ and $X Z$ performed all the experiments and data analysis. $L Z$ drafted manuscript. All authors participated in revising the manuscript and approved the final version.

\section{Funding}

This work was supported by funding from the National Science Foundation (grant no. 31770297). The funders had no role in the design of the study and collection, analysis, and interpretation of data and in writing the manuscript.

\section{Availability of data and materials}

The datasets used and/or analysed during the current study are available from the corresponding author on reasonable request.

Sequence data from this article can be found in the Arabidopsis Genome Initiative data library under the following accession numbers: NOA1

(At3g47450), NIA2 (At1g37130), CNGC6 (At2g23980), and Actin2 (At3g18780).

Ethics approval and consent to participate

Not applicable.

\section{Consent for publication}

Not applicable.

\section{Competing interests}

The authors declare that they have no competing interests for this research.

Received: 18 April 2019 Accepted: 13 August 2019

Published online: 20 August 2019

\section{References}

1. Lawas LMF, Zuther E, Jagadish SVK, Hincha DK. Molecular mechanism of combined heat and drought stress resilience in cereals. Curr Opin Plant Biol. 2018:45:212-7.

2. Farnese FS, Menezes-Silva PE, Gusman GS, Oliveira JA. When bad guys become good ones: the key role of reactive oxygen species and nitric oxide in the plant responses to abiotic stress. Front Plant Sci. 2016:7:471.

3. Senthil Kumar R, Shen CH, Wu PY, Suresh Kumar S, Hua MS, Yeh KW. Nitric oxide participates in plant flowering repression by ascorbate. Sci Rep. 2016; 6:35246.

4. Alderton WK, Cooper CE, Knowles RG. Nitric oxide synthases: structure, function and inhibition. Biochem J. 2001;357:593-615.

5. Guo FQ, Okamoto M, Crawford NM. Identification of a plant nitric oxide synthase gene involved in hormonal signaling. Science. 2003;302:100-3.

6. Flores-Pérez U, Sauret-Güeto S, Gas E, Jarvis P, Rodríguez-Concepción M. A mutant impaired in the production of plastome-encoded proteins uncovers a mechanism for the homeostasis of isoprenoid biosynthetic enzymes in Arabidopsis plastids. Plant Cell. 2008:20:1303-15.

7. Horchani F, Prévot M, Boscari A, Evangelisti E, Meilhoc E, Bruand C, Raymond P, Boncompagni E, Aschi-Smiti S, Puppo A, Brouquisse R. Both plant and bacterial nitrate reductases contribute to nitric oxide production in Medicago truncatula nitrogen-fixing nodules. Plant Physiol. 2011;55:1023-36.

8. Besson-Bard A, Pugin A, Wendehenne D. New insights into nitric oxide signaling in plants. Annu Rev Plant Biol. 2008;59:21-39.

9. Kim JY, Kwon YJ, Kim SI, Kim DY, Song JT, Seo HS. Ammonium inhibits chromomethylase 3-mediated methylation of the Arabidopsis nitrate reductase gene NIA2. Front Plant Sci. 2016;6:1161.

10. Xuan $Y$, Zhou S, Wang L, Cheng Y, Zhao L. Nitric oxide functions as a signal and acts upstream of AtCaM3 in thermotolerance in Arabidopsis seedlings. Plant Physiol. 2010;153:1895-906.

11. Lee $U$, Wie C, Fernandez BO, Feelisch M, Vierling E. Modulation of nitrosative stress by $\mathrm{S}$-nitrosoglutathione reductase is critical for thermotolerance and plant growth in Arabidopsis. Plant Cell. 2008;20:786-802. 
12. Wang L, Guo Y, Jia L, Chu H, Zhou S, Chen K, Zhao L. Hydrogen peroxide acts upstream of nitric oxide in the heat shock pathway in Arabidopsis seedlings. Plant Physiol. 2014;164:2184-96.

13. Parankusam S, Adimulam SS, Bhatnagar-Mathur P, Sharma KK. Nitric oxide (NO) in plant heat stress tolerance: current knowledge and perspectives. Front Plant Sci. 2017:8:1582.

14. Wu D, Chu H, Jia L, Chen K, Zhao L. A feedback inhibition between nitric oxide and hydrogen peroxide in the heat shock pathway in Arabidopsis seedlings. Plant Growth Regul. 2015;75:503-9.

15. Jha SK, Sharma M, Pandey GK. Role of cyclic nucleotide gated channels in stress management in plants. Curr Genomics. 2016;17:315-29.

16. Talke IN, Blaudez D, Maathuis FJ, Sanders D. CNGCs: prime targets of plant cyclic nucleotide signalling? Trends Plant Sci. 2003;8:286-93.

17. Shih HW, DePew CL, Miller ND, Monshausen GB. The cyclic nucleotidegated channel CNGC14 regulates root gravitropism in Arabidopsis thaliana. Curr Biol. 2005;25:3119-25.

18. Lu M, Zhang Y, Tang S, Pan J, Yu Y, Han J, Li Y, Du X, Nan Z, Sun Q AtCNGC2 is involved in jasmonic acid-induced calcium mobilization. J Exp Bot. 2016;67:809-19.

19. Gao QF, Gu LL, Wang HQ, Fei CF, Fang X, Hussain J, Sun SJ, Dong JY, Liu H, Wang YF. Cyclic nucleotide-gated channel 18 is an essential $\mathrm{Ca}^{2+}$ channel in pollen tube tips for pollen tube guidance to ovules in Arabidopsis. Proc Natl Acad Sci U S A. 2016:113:3096-101.

20. Gao F, Han X, Wu J, Zheng S, Shang Z, Sun D, Zhou RG, Li B. A heat-activated calcium-permeable channel - Arabidopsis cyclic nucleotide-gated ion channel 6 - is involved in heat shock responses. Plant J. 2012;70:1056-69.

21. Tunc-Ozdemir M, Tang C, Ishka MR, Brown E, Groves NR, Myers CT, Rato C, Poulsen LR, McDowell S, Miller G, Mittler R, Harper JF. A cyclic nucleotidegated channel (CNGC16) in pollen is critical for stress tolerance in pollen reproductive development. Plant Physiol. 2013;161:1010-20.

22. Finka A, Cuendet AFH, Maathuis FJM, Saidi Y, Goloubinoffa P. Plasma membrane cyclic nucleotide gated calcium channels control land plant thermal sensing and acquired thermotolerance. Plant Cell. 2012;24:3333-48.

23. Petersen $\mathrm{OH}$, Michalak M, Verkhratsky A. Calcium signalling: past, present and future. Cell Calcium. 2005;38:161-9.

24. Lamotte O, Courtois C, Dobrowolska G, Besson A, Pugin A, Wendehenne D. Mechanisms of nitric-oxide induced increase of free cytosolic $\mathrm{Ca}^{2+}$ concentration in Nicotiana plumbaginifolia cells. Free Radical Bio Med. 2006; 40:1369-76.

25. Jeandroz S, Lamotte O, Astier J, Rasul S, Trapet P, Basson-Bard A, Bourque S, Nicolas-Francès V, Ma W, Berkowitz GA, Wendehenne D. There's more to the picture than meets the eye: nitric oxide cross talk with $\mathrm{Ca}^{2+}$ signaling. Plant Physiol. 2013;163:459-70.

26. Lewis AM, Matzdorf SS, Rice KC. Fluorescent detection of intracellular nitric oxide in Staphylococcus aureus. Bio Protocol. 2016;6:e1878.

27. Liu HT, Sun DY, Zhou RG. Ca ${ }^{2+}$ and AtCaM3 are involved in the expression of heat shock protein gene in Arabidopsis. Plant Cell Environ. 2005;28:1276-84.

28. Mittler R. Abiotic stress, the field environment and stress combination Trends Plant Sci. 2006;11:15-9.

29. Sun AZ, Guo FQ. Chloroplast retrograde regulation of heat stress responses in plants. Front Plant Sci. 2016;7:398.

30. Palee S, Apaijai N, Shinlapawittayatorn K, Chattipakorn SC, Chattipakorn N. Acetylcholine attenuates hydrogen peroxide-induced intracellular calcium dyshomeostasis through both muscarinic and nicotinic receptors in cardiomyocytes. Cell Physiol Biochem. 2016;39:341-9.

31. Yu Y, Xie Q, Liu W, Guo Y, Xu N, Xu L, Liu S, Li S, Xu Y, Sun L. Increased intracellular $\mathrm{Ca}^{2+}$ decreases cisplatin resistance by regulating iNOS expression in human ovarian cancer cells. Biomed Pharmacother. 2017:86:8-15.

32. Carre $S$, Alberti $S$, Benesch JLP, Boelens W, Buchner J, Carver JA, Cecconi $C$, Ecroyd H, Gusev N, Hightower LE, Klevit RE, Leee HY, Liberek K, Lockwood B, Poletti A, Timmerman V, Toth ME, Vierling E, Wu T, Tanguay RM. Small heat shock proteins: multifaceted proteins with important implications for life. Cell Stree \& Chaperones. 2019;24:295-308.

33. Durner J, Wendehenne D, Klessig DF. Defense gene induction in tobacco by nitric oxide, cyclic GMP and cyclic ADP ribose. Proc Natl Acad Sci U S A. 1998:95:10328-33.

34. Lanteri ML, Pagnussat GC, Lamattina L. Calcium and calcium-dependent protein kinases are involved in nitric oxide and auxin-induced adventitious root formation in cucumber. J Exp Bot. 2006;57:1341-51.
35. Zheng SZ, Liu YL, Li B, Shang ZL, Zhou RG, Sun DY. Phosphoinositidespecific phospholipase C9 is involved in the thermotolerance of Arabidopsis. Plant J. 2012;69:689-700.

36. Gao K, Liu YL, Li B, Zhou RG, Sun DY, Zheng SZ. Arabidopsis thaliana phosphoinositide-specific phospholipase C isoform 3 (AtPLC3) and AtPLC9 have an additive effect on thermotolerance. Plant Cell Environ. 2014:55:1-11.

37. Kadota Y, Furuichi T, Sano T, Kaya H, Gunji W, Murakami Y, Muto S, Hasezawa S, Kuchitsu K. Cell-cycle-dependent regulation of oxidative stress responses and $\mathrm{Ca}^{2+}$ permeable channels NtTPC1A/B in tobacco BY-2 cells. Biochem Bioph Res Commun. 2005;336:1259-67.

38. Zhang W, Zhou RG, Gao YJ, Zheng SZ, Xu P, Zhang SQ, Sun DY. Molecular and genetic evidence for the key role of AtCaM3 in heat-shock signal transduction in Arabidopsis. Plant Physiol. 2009;149:1773-84.

39. Liu HT, Gao F, Li GL, Han JL, Liu DL, Sun DY, Zhou RG. The calmodulinbinding protein kinase 3 is part of heat-shock signal transduction in Arabidopsis thaliana. Plant J. 2008:55:760-73.

40. Liu HT, Li GL, Chang H, Sun DY, Zhou RG, Li B. Calmodulin binding protein phosphatase PP7 is involved in thermotolerance in Arabidopsis. Plant Cell Environ. 2007:30:156-64

41. Clough SJ, Bent AF. Floral dip: a simplified method for agrobacteriummediated transformation of Arabidopsis thaliana. Plant J. 1998:16:735-43.

42. Bradford MM. A rapid and sensitive method for the quantitation of microgram quantities of protein utilizing the principle of protein-dye binding. Anal Biochem. 1976;72:248-54.

43. Demidchik V, Tester M. Sodium fluxes through nonselective cation channels in the PM of protoplasts from Arabidopsis roots. Plant Physiol. 2002;128: $379-87$.

44. Wu Y, Xu X, Li S, Liu T, Ma L, Shang Z. Heterotrimeric G-protein participation in Arabidopsis pollen germination through modulation of a plasmamembrane hyperpolarization-activated $\mathrm{Ca}^{2+}$-permeable channel. New Phytol. 2007;176: 550-9.

45. Plieth C. Aequorin as a reporter gene. Methods Mol Biol. 2006;323:307-27.

\section{Publisher's Note}

Springer Nature remains neutral with regard to jurisdictional claims in published maps and institutional affiliations.
Ready to submit your research? Choose BMC and benefit from:

- fast, convenient online submission

- thorough peer review by experienced researchers in your field

- rapid publication on acceptance

- support for research data, including large and complex data types

- gold Open Access which fosters wider collaboration and increased citations

- maximum visibility for your research: over $100 \mathrm{M}$ website views per year

At $\mathrm{BMC}$, research is always in progress.

Learn more biomedcentral.com/submissions 